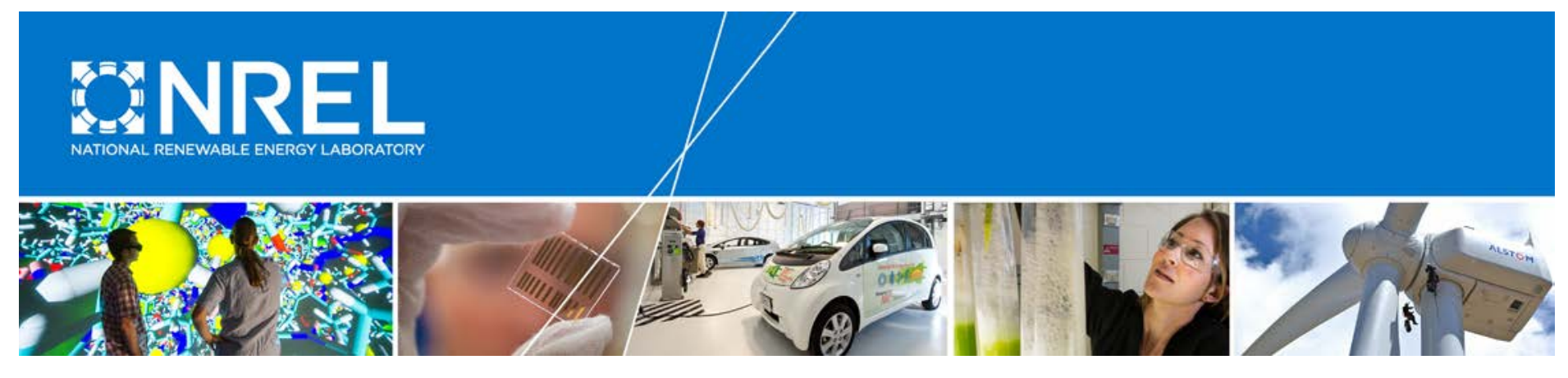

\title{
A Cost Effectiveness Analysis of Quasi-Static Wireless Power Transfer for Plug-In Hybrid Electric Transit Buses
}

\section{Preprint}

Lijuan Wang, Jeff Gonder, Evan Burton, Aaron Brooker, Andrew Meintz, and Arnaud Konan

Presented at the IEEE-Vehicular Power and Propulsion Conference 2015

Montreal, Quebec, Canada

October 19-22, 2015

(c) 2015 IEEE. Personal use of this material is permitted. Permission from IEEE must be obtained for all other uses, in any current or future media, including reprinting/republishing this material for advertising or promotional purposes, creating new collective works, for resale or redistribution to servers or lists, or reuse of any copyrighted component of this work in other works.

NREL is a national laboratory of the U.S. Department of Energy Office of Energy Efficiency \& Renewable Energy Operated by the Alliance for Sustainable Energy, LLC

This report is available at no cost from the National Renewable Energy Laboratory (NREL) at www.nrel.gov/publications.

\section{Conference Paper}

NREL/CP-5400-64089

November 2015 


\section{NOTICE}

The submitted manuscript has been offered by an employee of the Alliance for Sustainable Energy, LLC (Alliance), a contractor of the US Government under Contract No. DE-AC36-08GO28308. Accordingly, the US Government and Alliance retain a nonexclusive royalty-free license to publish or reproduce the published form of this contribution, or allow others to do so, for US Government purposes.

This report was prepared as an account of work sponsored by an agency of the United States government. Neither the United States government nor any agency thereof, nor any of their employees, makes any warranty, express or implied, or assumes any legal liability or responsibility for the accuracy, completeness, or usefulness of any information, apparatus, product, or process disclosed, or represents that its use would not infringe privately owned rights. Reference herein to any specific commercial product, process, or service by trade name, trademark, manufacturer, or otherwise does not necessarily constitute or imply its endorsement, recommendation, or favoring by the United States government or any agency thereof. The views and opinions of authors expressed herein do not necessarily state or reflect those of the United States government or any agency thereof.

This report is available at no cost from the National Renewable Energy Laboratory (NREL) at www.nrel.gov/publications.

Available electronically at SciTech Connect http:/www.osti.gov/scitech

Available for a processing fee to U.S. Department of Energy and its contractors, in paper, from:

U.S. Department of Energy

Office of Scientific and Technical Information

P.O. Box 62

Oak Ridge, TN 37831-0062

OSTI http://www.osti.gov

Phone: 865.576.8401

Fax: 865.576.5728

Email: reports@osti.gov

Available for sale to the public, in paper, from:

U.S. Department of Commerce

National Technical Information Service

5301 Shawnee Road

Alexandria, VA 22312

NTIS http://www.ntis.gov

Phone: 800.553 .6847 or 703.605 .6000

Fax: 703.605.6900

Email: orders@ntis.gov 


\title{
A Cost Effectiveness Analysis of Quasi-Static Wireless Power Transfer for Plug-In Hybrid Electric Transit Buses
}

\author{
Lijuan Wang, Jeff Gonder, Evan Burton, Aaron Brooker, Andrew Meintz and Arnaud Konan \\ National Renewable Energy Laboratory \\ System Analysis \& Integration Section \\ Golden, Colorado
}

\begin{abstract}
This study evaluates the costs and benefits associated with the use of a stationary-wireless-power-transferenabled plug-in hybrid electric bus and determines the cost effectiveness relative to a conventional bus and a hybrid electric bus. A sensitivity sweep was performed over many different battery sizes, charging power levels, and number/location of bus stop charging stations. The net present cost was calculated for each vehicle design and provided the basis for design evaluation. In all cases, given the assumed economic conditions, the conventional bus achieved the lowest net present cost while the optimal plug-in hybrid electric bus scenario beat out the hybrid electric comparison scenario. The study also performed parameter sensitivity analysis under favorable and high unfavorable market penetration assumptions. The analysis identifies fuel saving opportunities with plug-in hybrid electric bus scenarios at cumulative net present costs not too dissimilar from those for conventional buses.
\end{abstract}

Keywords-Quasi-static wireless power transfer, Conventional bus, Hybrid electric vehicle (HEV), Plug-in hybrid electric vehicle (PHEV), Hybrid electric bus (HEB), Plug-in hybrid electric bus (PHEB), Cost effectiveness analysis, Net present cost (NPC)

\section{INTRODUCTION}

In recent years, environmental concerns and high fuel prices have generated an increased interest in advanced propulsion systems for vehicles. Vehicle manufacturers also face demands to reduce harmful vehicle emissions in compliance with increasingly stringent regulations. Hybridization technologies have demonstrated their ability to significantly reduce the fuel cost for various vehicle applications. Plug-in hybrid electric vehicles (PHEVs) integrate large, grid-chargeable batteries that enable additional fuel displacement and potentially some amount of all-electric driving range. PHEV market penetration has been increasing, along with the range of technology options for vehicle charging. In the fairly near future, companies such as WiTricity, KAIST and WAVE hope to increase the convenience of garage and parking lot plug-in electric vehicle charging through the use of wireless power transfer [1-3]. A widely distributed network of public charging stations is important to provide the convenience and confidence required by PHEV drivers. Compared to personally owned vehicles, plug-in hybrid electric buses (PHEBs) may see even greater synergy with mid-route charging infrastructure, given that they normally operate on predictable routes of limited range.

\section{APPROACH}

\section{A. Charging Station Selection}

Eighteen days of driving data were collected from 20 conventional transit buses (CBs) in the Minneapolis, Minnesota, transit bus fleet. After removing vehicle-days with less than one mile of driving, this study applied the remaining 338 vehicle-days of driving data to support the analysis. The vehicle speed, fuel rate, and driving location (longitude and latitude) were recorded for each second during the data collection. Fig. 1 shows the driving routes of the 338 vehicledays from the collected data.

Two approaches were used when considering where to locate potential charging stations for use in the PHEB analysis scenarios: total stop time-based and stop frequency-based selections. The total stop time-based method was conducted by summing the total stop times at bus stops, and those stations with the longest stop times were selected to install the charging stations. For the frequency-based method, charging stations were located at those bus stops where the buses most frequently stopped. Figs. 2 and 3 show examples of the top 30 charging station locations from each method, mapped on the routes traversed by the 338 vehicle-day dataset.

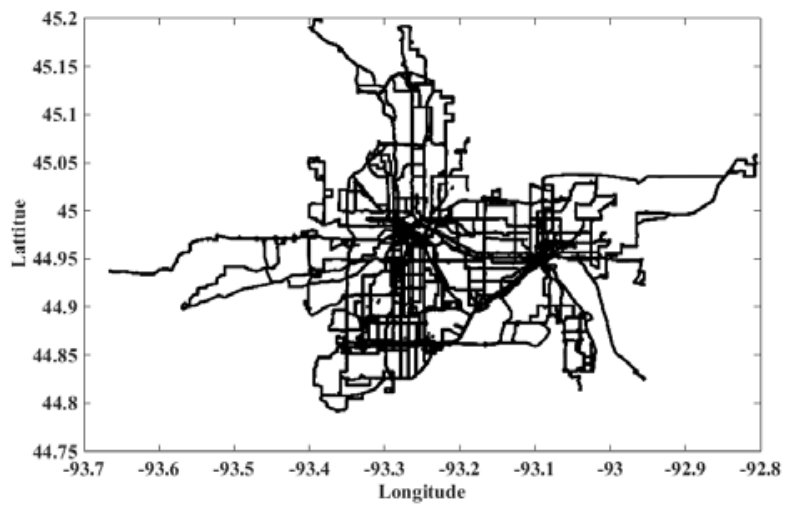

Fig. 1. Three hundred thirty-eight vehicle-days of transit bus routes 


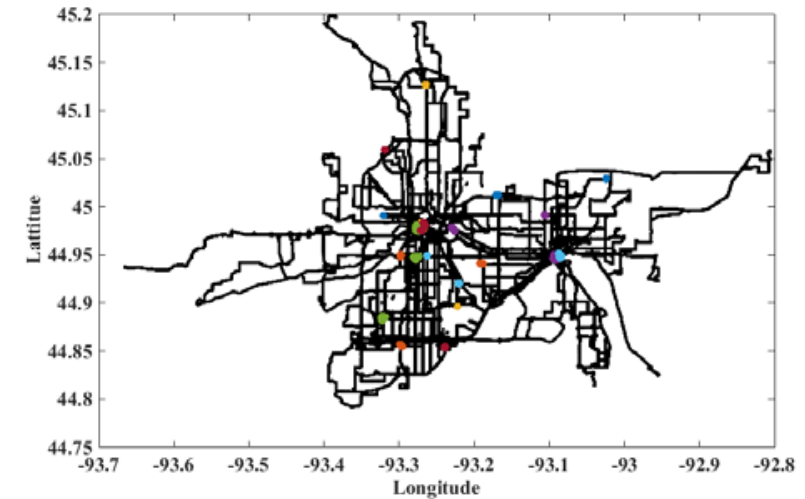

Fig. 2. Top thirty charging station locations selected using the total stop timebased approach

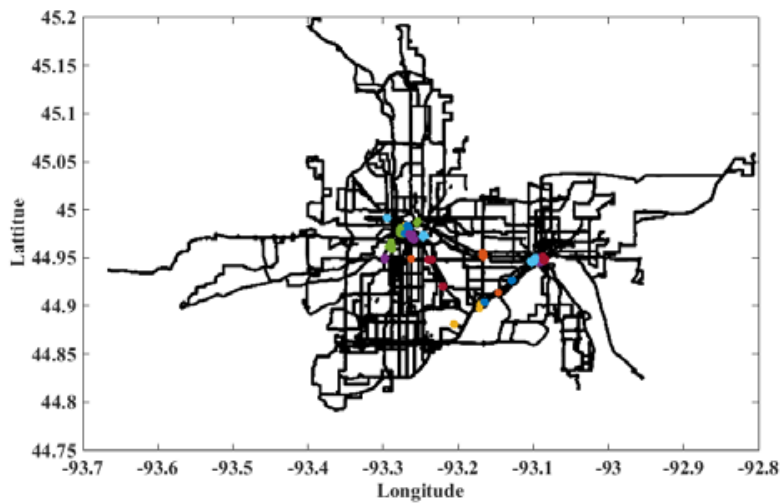

Fig. 3. Top thirty charging station locations selected using the stop frequencybased approach

\section{B. Economic Assumptions}

Table I summarizes the economic and input assumptions.

TABLE I. ASSUMPTIONS For PHEB COST-EFFECTIVENESS ANALYSIS

\begin{tabular}{|l|c|}
\hline \multicolumn{1}{|c|}{ Inputs } & Assumptions \\
\hline CB cost (\$) & $338,892[4]$ \\
\hline Hybrid electric bus (HEB) without battery cost (\$) & $491,951[4]$ \\
\hline Bus stop charging station cost (\$) & 500,000 \\
\hline Bus depot charging station cost for each vehicle (\$) & 5,000 \\
\hline Demand charge rate per month (\$/kW) & $12[5]$ \\
\hline Electricity cost (\$/kW) & $0.10[6]$ \\
\hline Five-year average diesel price (\$/gallon) & $3.71[6]$ \\
\hline Vehicle life (years) & $12[7]$ \\
\hline First battery cost (\$/kWh) & $500[8]$ \\
\hline Second battery cost (after 6 years) (\$/kWh) & 300 \\
\hline Battery markup factor & $1.5[9]$ \\
\hline Bus service days (days/year) & 350 \\
\hline Total buses in service & 679 \\
\hline Discount rate & 0.042 \\
\hline HEB average fuel economy (mpg) & 6.65 \\
\hline CB average fuel economy (mpg) & 5.29 \\
\hline PHEB efficiency in depleting mode $(\mathrm{kWh} / \mathrm{mi})$ & 2.10 \\
\hline 280 hp engine cost estimate $(\$)$ & 30,000 \\
\hline
\end{tabular}


The lifetime cost of PHEB with depot charging only includes the following six parts:

1. PHEB capital cost

2. Fuel cost

The annual fuel cost for the PHEB was calculated by equation 4 :

$$
\text { anPHEBFC }=\operatorname{serDay} * \text { avePHEBDailyFC }
$$

where anPHEBFC is the annual fuel cost for a PHEB, serDay is 350 service days, and avePHEBDailyFC is the simulated PHEB average daily fuel cost. The lifetime fuel cost is the sum of the PHEB fuel cost for 12 years, which was converted into the NPC using a discount rate of $4.2 \%$.

3. Electricity consumption cost at depot

Both consumption and demand charges are part of each electricity consumer's bill. The annual electricity cost calculation is shown in equation 5:

$$
\text { anElecCost }=\operatorname{serDay} * k w h D e p o t * \text { elecprice }
$$

where anElecCost is the annual electricity consumption cost for a PHEB, serDay is 350 service days, kwhDepot is the average daily electricity consumption for a PHEB at the depot, and elecprice is electricity price. The lifetime electricity consumption cost was the sum of the PHEB electricity consumption cost for 12 years, which was converted into the NPC using a discount rate of $4.2 \%$.

4. Electricity demand cost at depot

The electricity demand cost at the depot was given by equation 6 :

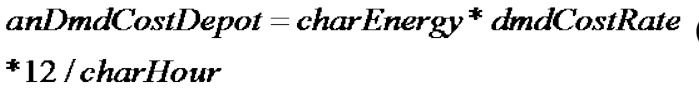

where anDmdCostDepot is the PHEB's annual electricity demand cost at the depot, charEnergy is the battery size, dmdCostRate is demand charge rate per month, and charHour is assumed to be 5 hours (for an overnight charge). The lifetime electricity demand cost at the depot was the sum of the PHEB electricity demand cost for 12 years, which was converted into the NPC using a discount rate of $4.2 \%$.

\section{Battery cost}

The battery cost was calculated by equation 7 :
battCost $=$ battSize $*$ unitBattCost $1 *$ markupFactor + battSize* unitBattCost $2 *$ markupFactor

where battCost is the battery cost, battSize is the battery size in $\mathrm{kWh}$, unitBattCost1 is the first battery cost $(\$ / \mathrm{kWh})$, and unitBattCost 2 is the second battery cost $(\$ / \mathrm{kWh})$ (after 6 years). Note that all values assume "usable" $\mathrm{kWh}$.

6. Depot charging infrastructure cost for each bus

The cost of depot charging infrastructure in this study is assumed to be $\$ 5,000$ for each bus.

- Lifetime cost calculation of PHEB with both depot and bus stop charging

In addition to the costs for depot charging only, the costs of a PHEB with both depot and bus stop charging include two more parts.

7. Electricity cost at bus stop charging stations, which includes electricity consumption cost and electricity demand cost.

The electricity consumption costs were calculated in a similar manner as equation 5 for the bus depot charging. The electricity demand cost assigned to each bus for bus stop charging was computed by equation 8 :

$$
\begin{aligned}
& \text { anDmdCost }=\text { charPwr } * \text { dmdCostRate } \\
& * 12 * \text { statAmount / busAmount }
\end{aligned}
$$

where anDmdCost is the PHEB's annual electricity demand cost for bus stop charging, charPwr is the charging power, dmdCostRate is the demand charge rate per month, statAmount is the number of charging stations, and busAmount is the number of PHEBs over which the charging station costs are spread. The lifetime electricity demand cost was the sum of the PHEB electricity demand cost at a bus stop for 12 years, which was converted into the NPC using a discount rate of $4.2 \%$. It should be noted that each station was assumed to have its own meter and thus the demand charge is calculated for each stop separately.

8. Charging station infrastructure cost, which was calculated by equation 9 :

$$
\begin{aligned}
& \text { charStatCost }=\text { statCost } * \\
& \text { statAmount / totalBusAmount }
\end{aligned}
$$

where charStatCost is the is the charging station infrastructure cost for each vehicle, statCost is the cost of each charging station, statAmount is the 
number of bus stop charging stations, and totalBusAmount is the total number of buses benefiting from the stations over which the station costs are spread.

\section{- Lifetime cost calculation of all-electric bus}

The calculation of the lifetime cost of an all-electric bus is the same as that of the PHEB, except that the fuel cost is not included and the cost of the engine is subtracted.

\section{ANALYSIS AND RESULTS}

\section{A. Design of Experiments}

Table II shows a full factorial design over a number of different battery sizes, charging power levels, and number of charging stations. Following a complete simulation of the design matrix, all combinations of battery size, charging power, and number of charging stations were evaluated according to the assumptions in Table I. The NPC was calculated for each vehicle design and provided the basis for design evaluation.

TABLE II. DESIGN OF EXPERIMENTS MATRIX

\begin{tabular}{|c|c|c|c|}
\hline Parameter & Low & High & Step \\
\hline $\begin{array}{ll}\text { Battery } & \text { energy } \\
(\mathrm{kWh}) & \end{array}$ & 30 & 80 & 10 \\
\hline $\begin{array}{l}\text { Charging power } \\
(\mathrm{kW})\end{array}$ & 50 & 250 & 20 \\
\hline $\begin{array}{l}\text { Charging station } \\
\text { amount }\end{array}$ & 5 & 30 & 1 \\
\hline
\end{tabular}

\section{B. Results for Charging at Both Charing Station Selection Approches}

It was found that installing 21 charging stations was the most cost effective for the total stop time-based bus stop charger selection approach. The NPC is shown in Fig. 4, with battery size plotted on the horizontal axis and charging power plotted on the vertical axis. The two-dimensional space reflects 66 combinations investigated. Designs that would require battery charging at rates greater than four times the battery's rated energy were excluded. For the charging stations selected using the stop frequency-based approach, installing 15 charging stations gave the lowest NPC, which is summarized in Fig. 5. It should be noted that both analyses assumed no changes to bus dwell time. It can be seen from comparing these two plots that the total idle time-based charging station selection approach was more cost effective. This may partially be due to the fact that the charging stations were more evenly distributed when applying the total stop time-based approach. Of the three powertrain vehicles, given the assumed economic conditions, the CB achieved the lowest NPC. The fuel savings for the optimal PHEB scenario (NPC $=\$ 763,000$ at $40-\mathrm{kWh}$ battery and $150-\mathrm{kW}$ charging power) are insufficient to offset its upfront cost increment, resulting in a $14 \%$ higher cost for the PHEB relative to the $\$ 668,000 \mathrm{NPC}$ for the CB. The optimal PHEB scenario achieved a 1\% lower lifetime cost than the HEB.

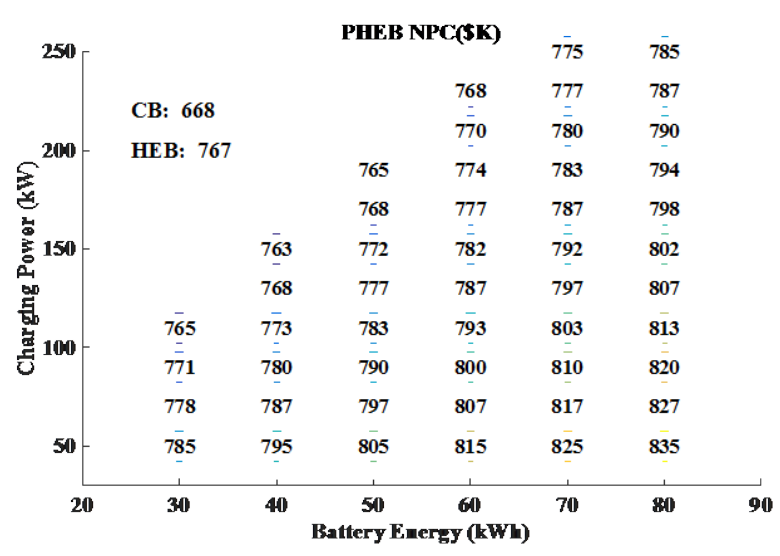

Fig. 4. NPC of total stop time-based approach

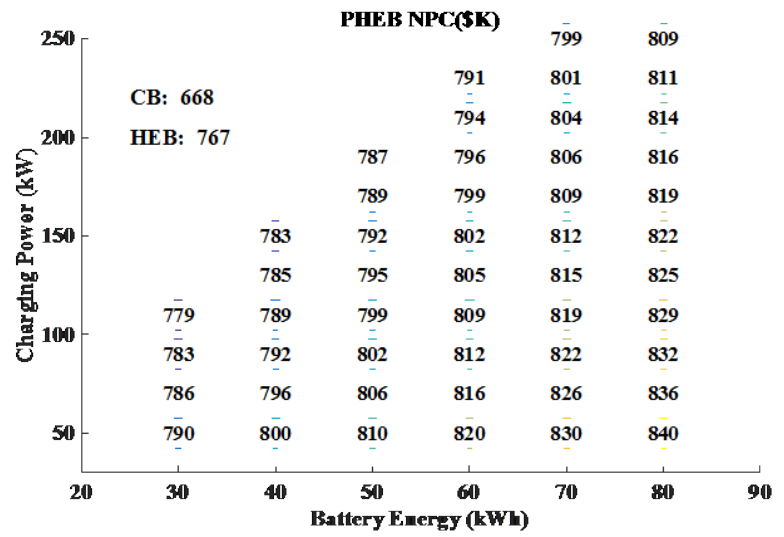

Fig. 5. NPC of stop frequency-based approach

Fig. 6 shows the lifetime fuel use and cost breakdown for the $\mathrm{CB}, \mathrm{HEB}$ and the optimal PHEB scenario, and Fig. 7 shows the same cost information alongside the lifetime fuel savings relative to the $\mathrm{CB}$.. Even though the PHEB savings are insuffficient to totally offset its upfront cost increment, the PHEB reduces lifetime diesel fuel use by $78 \%$ relative to the 115,000-gallon lifetime consumption estimate for the $\mathrm{CB}$, whereas the HEB scenario reduces fuel use relative to the $\mathrm{CB}$ by $20 \%$.

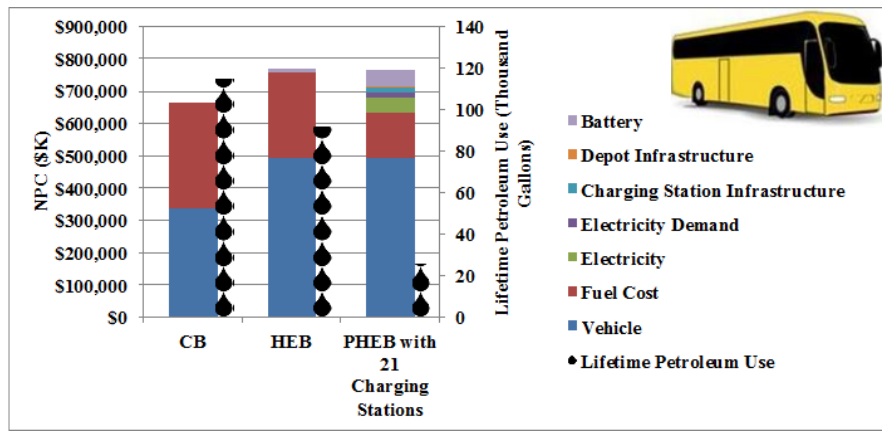

Fig. 6. Lifetime cost breakdown and fuel use 


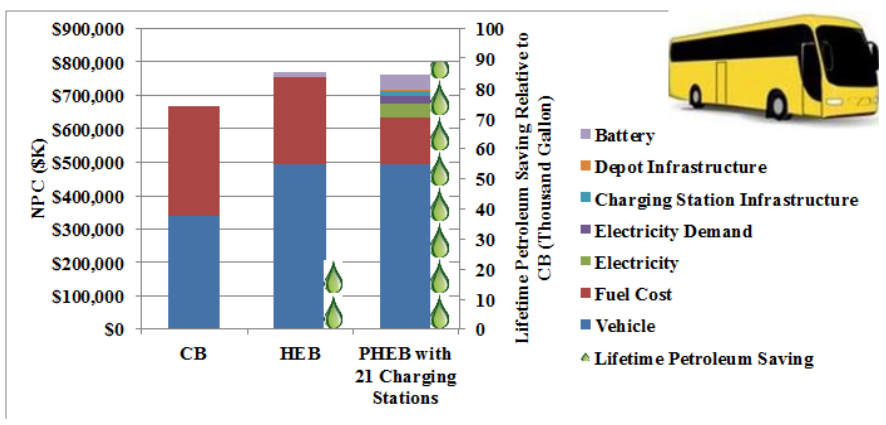

Fig. 7. Lifetime cost breakdown and fuel savings

\section{Results for All-Electric Bus}

The results also indicated that 1,231 out of 22,308 simulation cases (the combination of 6 battery sizes, 11 charging power levels, and 338 vehicle-days) could run in allelectric mode for the entire driving day. The distances in electric battery mode are variously depicted in Figs. 8 through 10 with battery size plotted on the horizontal axis and charging power plotted on the vertical axis. The three-dimensional plot (Fig. 8) visually demonstrates the maximum (blue dots) and average (red dots) distance with different combination of battery size and charging power. Fig. 9 and Fig. 10 explicitly provide the respective maximum and average EV trip distances achieved over the design space. Fig. 9 shows that the drive range can reach 195 miles in scenarios with an $80-\mathrm{kWh}$ battery, $230-\mathrm{kW}$ charging power, and 21 charging stations. Fig. 11 shows the EB NPC calculated based on the daily average travel distance assumption in Fig. 10. It indicates that NPC for the EB is higher than for the HEV when the average driving range is greater than 34 miles.

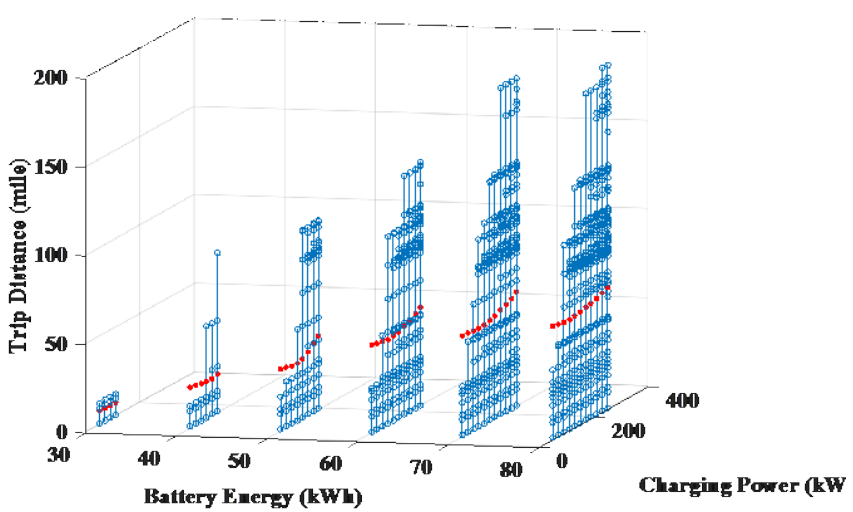

Fig. 8. Maximum (blue dots) and average (red dots) PHEB distance achieved in all-electric mode

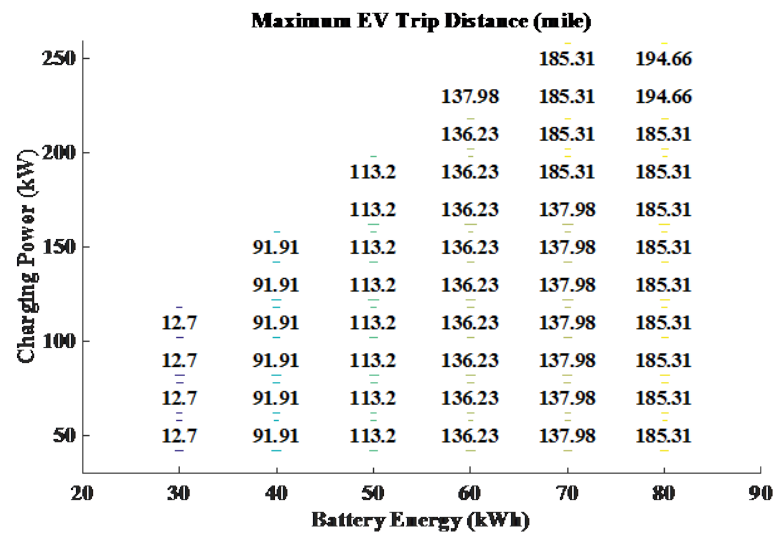

Fig. 9. Maximum PHEB distance achieved in all-electric mode

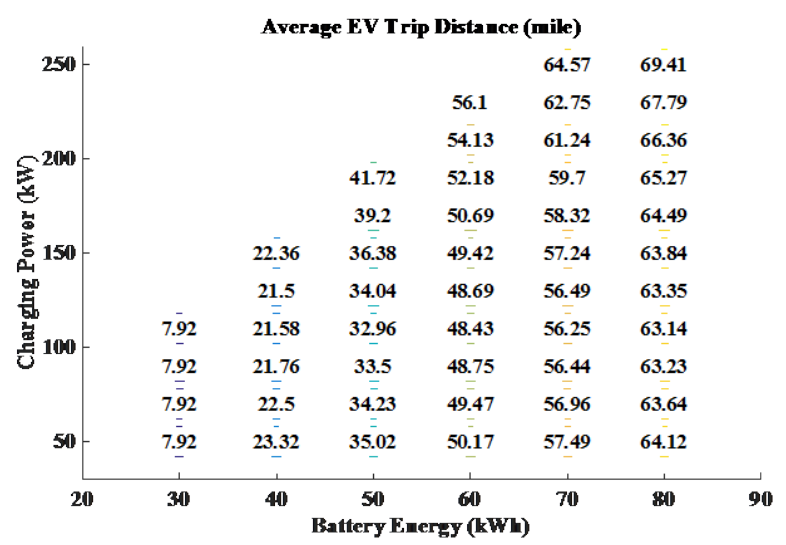

Fig. 10. Average PHEB distance achieved in all-electric mode

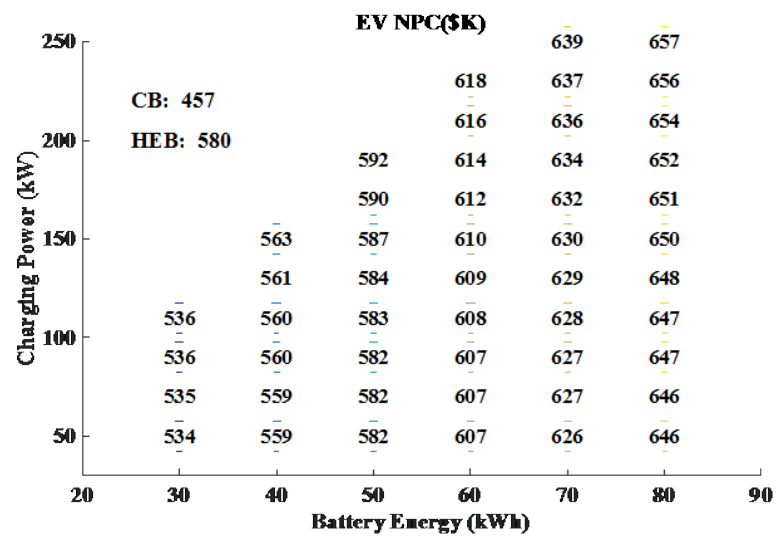

Fig. 11. NPC for vehicle-days that can be completed by the PHEB in allelectric mode

\section{Sensitivity Analysis}

To investigate the effects on cost effectiveness, sensitivity analyses were executed under two alternate sets of economic assumptions:

- Unfavorable conditions for PHEB market penetration: Low fuel price and high battery, electricity, and charging station infrastructure cost

- Favorable conditions for PHEB market penetration: High fuel price and low battery, electricity, and charging station infrastructure cost 
The two sets of assumptions are listed in Table III, and the NPCs under each scenario are illustrated in Figs. 12 and 13. The analysis indicated NPC is highly sensitive to assumptions about economic climate. Fig. 12 shows that the NPC of the PHEB scenario is lower that that of the $\mathrm{CB}$ scenario under the favorable PHEB economic conditions set of assumptions, whereas Fig. 13 shows that the unfavorable PHEB economic conditions set of assumptions causes the PHEB to be the least cost effective.

TABLE III. High/LOW MARKET Potential ASSUMPTIONS

\begin{tabular}{|l|c|c|}
\hline \multicolumn{1}{|c|}{ Assumptions } & \multicolumn{1}{|c|}{$\begin{array}{c}\text { Favorable } \\
\text { Market } \\
\text { Potential } \\
\text { Scenario }\end{array}$} & $\begin{array}{c}\text { Unfavorable } \\
\text { Market } \\
\text { Potential } \\
\text { Scenario }\end{array}$ \\
\hline $\begin{array}{l}\text { Bus stop charging station } \\
\text { cost (\$) }\end{array}$ & 300,000 & 700,000 \\
\hline $\begin{array}{l}\text { Depot charging station cost } \\
\text { for each vehicle (\$) }\end{array}$ & 3000 & 7000 \\
\hline Electricity cost (\$/kWh) & 0.08 & 0.12 \\
\hline $\begin{array}{l}\text { Demand charge } \\
\text { (\$/kW/month) }\end{array}$ & 10 & 14 \\
\hline Diesel cost (\$/gallon) & 5.00 & 2.50 \\
\hline First battery cost (\$kWh) & 500 & 600 \\
\hline $\begin{array}{l}\text { Second battery cost (after 6 } \\
\text { years) }(\$ \mathrm{kWh})\end{array}$ & $\begin{array}{l}\text { (no battery } \\
\text { replacement) }\end{array}$ & 400 \\
\hline
\end{tabular}

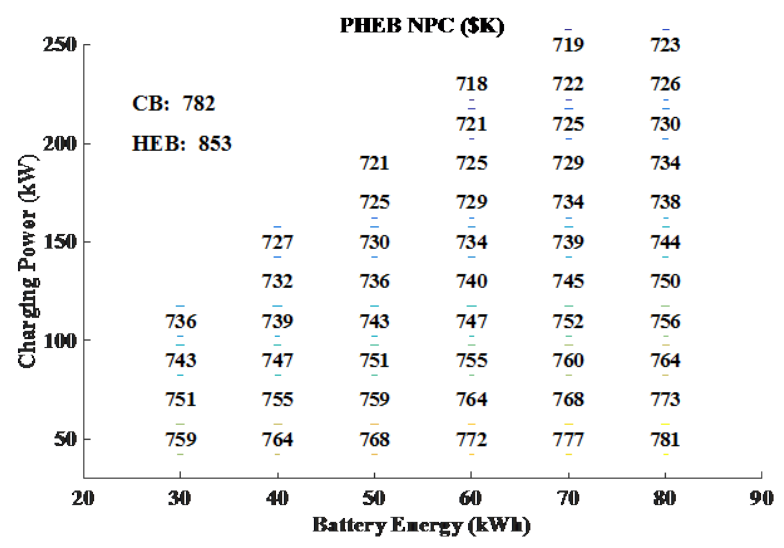

Fig. 12. NPC at favorable market potential assumptions

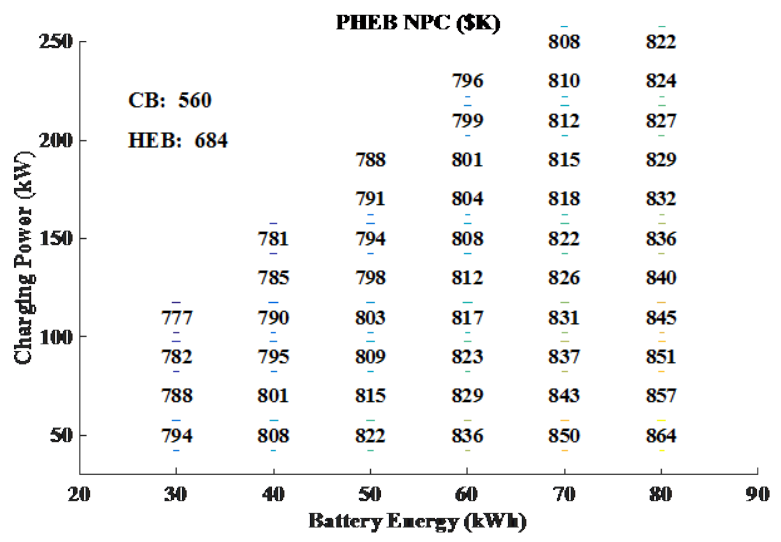

Fig. 13. NPC at unfavorable market potential assumptions

\section{CONCLUSION}

This analysis has examined two charging station selection approaches and concluded that the total stop time-based method achieved more favorable benefits. Real-world vocational data and multiple sets of economic assumptions have been employed for the cost effectiveness analysis. Given the baseline set of economic assumptions, the optimized PHEB scenarios were unable to outpace the NPC of the CB. However, the PHEB reduces lifetime diesel fuel use by $78 \%$ relative to the 115,000-gallon lifetime consumption estimate for the $\mathrm{CB}$, whereas the HEB scenario achieves a $20 \%$ reduction relative to the CB.

Future work in the related area will include cost effectiveness analysis from the fleet (rather than average individual vehicle) perspective. Additional research will investigate incremental rollout of PHEBs and chargers, beginning with the most favorable route and bus stop locations.

\section{REFERENCES}

[1] WiTricity Automotive website, witricity.com/applications/automotive. Accessed September 24, 2014.

[2] Wireless Power Transimission Would Let EVs Draw Their Power from the Road, http://electricvehicle.ieee.org/advanced-charging/the-allelectric-car-you-never-plug-in/.

[3] WAVE Wireless Charing Electric Vehicles, http://www.waveipt.com/\#!/

[4] U.S. Department Of Transportation, Federal Transit Administration, "Additional transit bus life cycle cost scenarios based on current and future fuel prices," Final Report, pp. 12, September 2008.

[5] Electric Schedule A-10 Medium General demand-metered service, Pacific Gas and Electric Company, San Francisco, California, U 39.

[6] U.S. Energy Information Administration (EIA) Website, http://www.eia.gov, Accessed on March 31, 2015.

[7] U.S. Department of Transportation, Federal Transit Administration, "Useful Life of Transit Buses and Vans," Report No. FTA VA-26-722907.1, pp. iv, April 2007.

[8] The EV Everywhere Challenge, http://energy.gov/sites/prod/files/2014/05/f15/APR13 Energy_Storage c II EV Everywhere 1.pdf, accesed on April 8, 2015

[9] A. Rogozhin, M. Gallaher, G. Helfand, and W. McManus, "Using indirect cost multipliers to estimate the total cost of adding new technology in the automobile industry," International Journal of Production Economics, vol. 124, iss. 2, pp. 360-368, April 2010.

[10] National Renewable Energy Laboratory, "Future Automotive System Technology Simulator," http://www.nrel.gov/transportation/fastsim.html

\section{ACKNOWLEDGMENTS}

This work was supported by the U.S. Department of Energy under Contract No. DE-AC36-08GO28308 with the National Renewable Energy Laboratory. Funding was provided U.S. DOE Office of Energy Efficiency and Renewable Energy Vehicle Technologies Office.

The U.S. Government retains and the publisher, by accepting the article for publication, acknowledges that the U.S. Government retains a nonexclusive, paid-up, irrevocable, worldwide license to publish or reproduce the published form of this work, or allow others to do so, for U.S. Government purposes. 